IJHG

26,3

Received 4 December 2020 Revised 22 January 2021 Accepted 10 February 2021

\section{The role of organizational factors in how efficiency-thoroughness trade-offs potentially affect clinical quality dimensions - a review of the literature}

\author{
Malin Knutsen Glette \\ Faculty of Health Sciences, SHARE - Centre for Resilience in Healthcare, \\ University of Stavanger, Stavanger, Norway and \\ Faculty of Health, Western Norway University of Applied Sciences, \\ Haugesund, Norway, and \\ Siri Wiig \\ Faculty of Health Sciences, SHARE - Centre for Resilience in Healthcare, \\ University of Stavanger, Stavanger, Norway
}

\begin{abstract}
Purpose - The purpose of this paper is to increase knowledge of the role organizational factors have in how health personnel make efficiency-thoroughness trade-offs, and how these trade-offs potentially affect clinical quality dimensions.

Design/methodology/approach - The paper is a thematic synthesis of the literature concerning health personnel working in clinical, somatic healthcare services, organizational factors and clinical quality.

Findings - Identified organizational factors imposing trade-offs were high workload, time limits, inappropriate staffing and limited resources. The trade-offs done by health personnel were often trade-offs weighing thoroughness (e.g. providing extra handovers or working additional hours) in an environment weighing efficiency (e.g. ward routines of having one single handover and work-hour regulations limiting physicians' work hours). In this context, the health personnel functioned as regulators, balancing efficiency and thoroughness and ensuring patient safety and patient centeredness. However, sometimes organizational factors limited health personnel's flexibility in weighing these aspects, leading to breached medication rules, skipped opportunities for safety debriefings and patients being excluded from medication reviews.

Originality/value - Balancing resources and healthcare demands while maintaining healthcare quality is a large part of health personnel's daily work, and organizational factors are suspected to affect this balancing act. Yet, there is limited research on this subject. With the expected aging of the population and the subsequent pressure on healthcare services' resources, the balancing between efficiency and thoroughness will become crucial in handling increased healthcare demands, while maintaining highquality care.
\end{abstract}

Keywords Healthcare quality, Clinical quality, Patient safety, Efficiency-thoroughness trade-offs, ETTO-Principle, Thematic literature synthesis, Literature review

Paper type Literature review

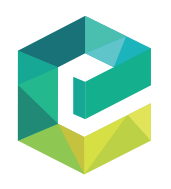

(C) Malin Knutsen Glette and Siri Wiig. Published by Emerald Publishing Limited. This article is published under the Creative Commons Attribution (CC BY 4.0) licence. Anyone may reproduce, distribute, translate and create derivative works of this article (for both commercial and non-commercial purposes), subject to full attribution to the original publication and authors. The full terms of this licence may be seen at http://creativecommons.org/licences/by/4.0/legalcode

Funding: The publication of this study was funded by The university of Stavanger, Faculty of Health Sciences. The funding body was not involved in the research process (design of the study, data collection, analysis) or in writing the manuscript. Governance Vol. 26 No. 3, 2021 pp. $250-265$ Emerald Publishing Limited 2059-4631

DOI 10.1108/IJHG-12-2020-0134
International Journal of Health 


\section{Introduction}

Resource limitation is an issue in healthcare services worldwide. Healthcare demands are unlimited, the costs are increasing and the resources are consequently restricted (Keliddar et al., 2017). Simultaneously, healthcare quality is high on the agenda for policymakers internationally and is viewed as an important aspect of health system performance, despite existing variations in care outcomes within, and between, different healthcare services (Busse et al., 2019). To maintain high-quality healthcare services in the face of increasing demands and decreasing access to resources, a continuous balancing between these two aspects is necessary. In the perspective of the efficiency-thoroughness trade-off principle (ETTO principle) (Hollnagel, 2009), this means that healthcare workers need to do trade-offs between what is efficient (keeping the resource use low) and what is thorough (achieving the intended outcome and avoiding error). Such trade-offs are, according to Hollnagel (2009), a normal and necessary part of health personnel's everyday effort to keep the healthcare service running, as it is not possible to emphasize both efficiency and thoroughness at the same time. Yet, an unbalance between the two, where one is weighted over the other, may lead to errors and adverse events (Hollnagel, 2009).

Organizational factors such as health personnel's competence, health personnel's working conditions, availability to resources and health services management play an important role in the attempt to achieve the right ETTO balance (Mosadeghrad, 2014; Grant and Guthrie, 2018; Sujan et al., 2015). Organizations often have, more or less, clearly defined goals, a structure and a management system, a culture, a set of values and a way to cooperate (Bate, 2008). These aspects result in work-related prerequisites, which affect the health personnel's working conditions. Moreover, healthcare systems are complex, ever-changing systems with multiple levels and multiple actors, leading to a great number of actions, processes and interactions (Braithwaite et al., 2013). This is producing an array of organizational factors which can affect health personnel, patients and the overall healthcare quality. Additionally, the organizational culture, including values, rituals, norms and behaviors among healthcare workers, may affect how efficiency-thoroughness is weighted, and there again impact healthcare quality (Davies et al., 2000).

Quality in healthcare services is by the Institute of Medicine (IOM) defined as "the degree to which health care services for individuals and populations increase the likelihood for desired health outcomes and are consistent with current professional knowledge" (AHRQ, 2015). The description of the quality term is often centered on conceptional dimensions such as IOM's six domains for healthcare quality. In short, these domains involve avoid harm; provide services based on scientific knowledge; refrain from providing services to those who are not likely to benefit from it; provide care in accordance with the patients values, references and needs; reduce waits and sometimes harmful delays; avoid waste (e.g. equipment, supplies or energy) and provide equitable care (care that is similar to all, regardless of, e.g. gender, ethnicity or geographic location) (AHRQ, 2015). There are, however, differences in how the quality concept is interpreted, resulting in different perceptions of what Healthcare quality involves among different levels in the healthcare system and different groups of healthcare workers (Wiig et al., 2014). In an ETTO perspective, this may involve differences in how efficiency versus thoroughness is prioritized (Li et al., 2017).

Although balancing resources and healthcare demands is a large part of healthcare personnel's everyday work (Hollnagel, 2009) and organizational factors are suspected to affect this balancing act, there is limited research on how organizational factors affect ETTOs and how these trade-offs may affect clinical quality dimensions.

\section{Purpose of the study}

The purpose of this study was to increase knowledge of the role organizational factors play in how health personnel make efficiency-thoroughness trade-offs (cf. Hollnagel's ETTO-

\section{Efficiency- thoroughness trade-offs}


IJHG

26,3

principle) and how it potentially affects the quality of the provided healthcare services. The study aimed to answer the following research question: What role do organizational factors have in how healthcare personnel make efficiency-thoroughness trade-offs, and how does it potentially affect clinical quality dimensions?

\section{Method}

The study was conducted as a thematic synthesis of the literature (Thomas and Harden, 2008). A thematic synthesis of the literature involves extensive literature searches (e.g. searches in applicable databases, hand searches in relevant journals and searches for gray literature) and have proven constructive in recent health services research (Halvorsen $e t$ al., 2020; van Leeuwen et al., 2019). Although the screening process of a thematic synthesis is comprehensive, its purpose is not to provide an exhaustive sample of the literature but rather to present a purposive sample of the relevant literature to answer the present research question (Thomas and Harden, 2008). For accurate reporting, the synthesis applied the PRISMA float diagram (Figure 2) (Moher et al., 2015).

\section{Inclusion criteria}

To be eligible for inclusion, studies need to be published in scientific journals with peer review. The studies had to be written in English or Nordic languages and to have a clear methodological design (qualitative or quantitative). Qualified studies had to be published within a ten-year frame (2010-2020) to avoid inclusion of outdated research results. Further requirements were that the studies needed to involve health personnel working in clinical, somatic healthcare services (e.g. nurses, physicians, pharmacists), organizational factors (e.g. requirements or routines, work schedules, access to equipment, staffing or workload) and clinical quality (e.g. safe, effective, timely care). Studies exclusively involving patient experiences, psychiatric healthcare services or an overall systemic perspective (not including healthcare personnel), for example, focusing on cost-efficiency, were not included.

\section{Identification of studies - search strategy and databases}

All searches were conducted by MKN, whilst SW participated in the screening process by discussing and assessing individual studies. Initial literature search was conducted in the databases Academic Search Elite via EBSCOhost, Cinahl via EBSCOhost, Medline via EBSCOhost, PubMed via National Library of Medicine (NHI) and Scopus via ELSEVIER to identify the most relevant databases. Search words used in the initial phase were efficiencythoroughness trade-offs, trade-offs, clinical quality and organizational factors in different combinations, resulting in seven articles of interest. Furthermore, expanded searches were conducted in Academic Search Elite, Medline and Scopus, adding the words performance variability, adaptation, trade-off, optimality-brittleness, ETTO-principle and system management combined with the MESH entry terms quality of healthcare/healthcare quality and ergonomics (the search term optimality-brittleness was excluded from the search after 31 searches without any hits). The overall search resulted in 11 articles of interest. All articles were then screened for relevant search words, generating new searches in the databases Academic Search Elite, Medline, PubMed and Scopus, with the words workarounds, reprioritizing and conflicting goals. Three articles of interest were identified. Moreover, a discussion with the co-author of the study generated five additional search words concerning organizational culture and leadership (organizational culture, culture, organizationallearning, teamwork, leadership). Searches were conducted in combination with the previously mentioned words in the same databases and yielded five articles of interest (see Figure 1 for an overview of the search process). Lastly, secondary searches were conducted in the reference list of the identified articles in addition to hand searches within relevant journals 


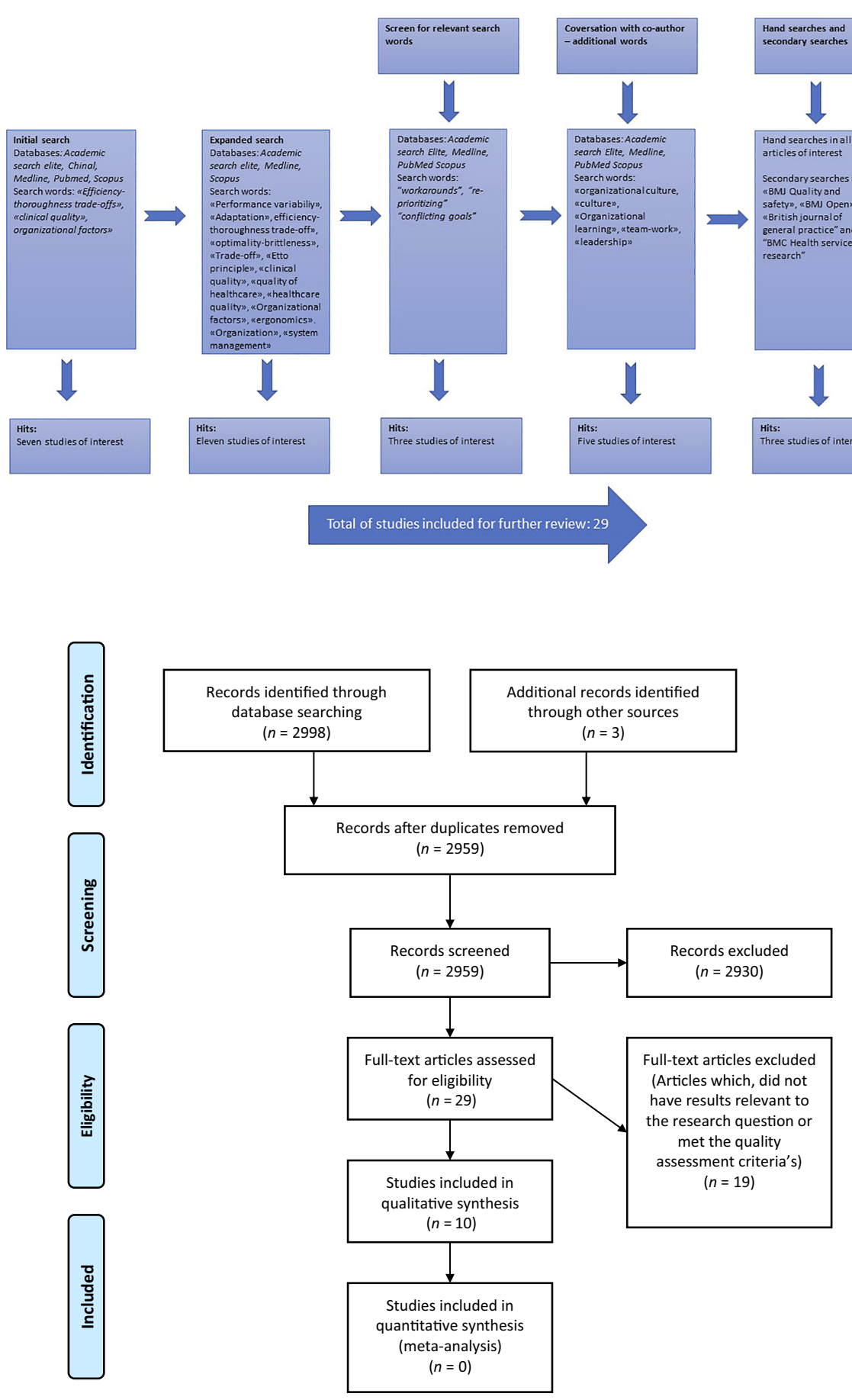

Figure 2.

The PRISMA float diagram 
IJHG

26,3

(BMJ Quality and Safety, BMJ Open, British Journal of General Practice and BMC Health Services Research), resulting in three articles of interest. Searches were conducted from June to September 2020, and resulted in a total of 29 articles included for further review (for full overview of searches, see attachment I).

\section{Selection of studies}

The 29 studies were read in full text to determine their eligibility for inclusion. Decisions on inclusion were based on the inclusion/exclusion criteria stated above. After the review, 11 articles, directly or indirectly, focusing on ETTOs, organizational factors and clinical quality, were included and 18 articles excluded. Of the included studies, one study had a crosssectional design, nine studies had qualitative designs and one study was a mixed method study. Included studies were entered into the reference manager Endnote. The overall selection process is demonstrated in the PRISMA flow diagram (Figure 2).

Quality assessment

Studies with qualitative design were assessed using Critical Appraisal Skills Program (CASP) for qualitative studies (Critical Appraisal Skills Programme, 2019). The crosssectional study was assessed using the National Heart, Lung and Blood Institute's (NIH) "Quality assessment tool for Cross sectional and Observational cohort studies" (National Heart Lung and Blood Institute). The mixed method study was assessed through the "Mixed Methods Appraisal Tool" (MMAT) (Hong et al., 2018). Overall, the studies had high-quality rating, with the exception of the cross-sectional study, which had a low response rate (less than $50 \%$ ) and was excluded from the literature synthesis. After the quality assessment, a total of 10 studies were included in the review (for a complete overview of the included studies, see Table 1).

\section{Data extraction and analysis}

The first phase of the data analysis consisted of extracting information related to the research question at hand. MKN led the extraction process and the analysis work, while SW contributed in discussions regarding the data extraction process and analysis. The focus was primarily on organizational factors, trade-offs and clinical quality, while still staying open for other, potentially relevant results (Thomas and Harden, 2008). Eligible results were entered verbatim in a word table under major headings (organizational factors, trade-offs and clinical quality). Thomas and Harden (2008) state that it, in many cases, can be challenging to identify "key concepts" when extracting data (results) from qualitative studies, and did in their approach compromise all identified results in their analysis. In the current synthesis, it was, however, possible to extract key concepts relevant to the current research question. Therefore, the data were refined (data with limited relevance for the research question were weeded out) in the second part of the analysis. The remaining data were then, first, organized under broad categories (e.g. trade-offs challenging thoroughness and trade-offs challenging efficiency), before smaller, more precise categories (subcategories) were developed (e.g. tradeoffs imposed by time constraints or planned measures to ensure efficiency) (see Table 2, for an example of the analysis). The subcategories were altered several times to make them as accurate as possible, and the content (the extracted data) moved back and forth to identify their best fit within the different categories. Further, all categories and subcategories were assembled into one scheme and given color codes to find patterns or consistencies between the three major headings (organizational factors, trade-offs, clinical quality). Finally, the analysis resulted in four main categories describing what role organizational factors have in how healthcare personnel make efficiency-thoroughness trade-offs, and how it potentially 


\begin{tabular}{|c|c|c|c|c|}
\hline Title/Author & Method & Setting & Main focus & \\
\hline $\begin{array}{l}\text { 1. Efficiency versus } \\
\text { thoroughness in medication } \\
\text { review: a qualitative interview } \\
\text { study in UK primary care } \\
\text { (Duncan } \text { et al., 2019) }\end{array}$ & $\begin{array}{l}\text { Qualitative } \\
\text { interview study }\end{array}$ & Primary care & $\begin{array}{l}\text { Experience of medication } \\
\text { reviews in general practice } \\
\text { (pharmacists and GPs) }\end{array}$ & trade-of \\
\hline $\begin{array}{l}\text { 2. To leave or to lie? Are concerns } \\
\text { about a shift-work mentality and }\end{array}$ & $\begin{array}{l}\text { Qualitative } \\
\text { (interviews and }\end{array}$ & Hospital wards & $\begin{array}{l}\text { The tension between } \\
\text { committing to duty hour rules }\end{array}$ & 255 \\
\hline $\begin{array}{l}\text { eroding professionalism as a } \\
\text { result of duty hour rules } \\
\text { justified? (Szymczak et al., 2010) }\end{array}$ & observations) & & $\begin{array}{l}\text { or committing to the patients' } \\
\text { needs (hospital physicians) }\end{array}$ & \\
\hline $\begin{array}{l}\text { 3. The role of dynamic trade-offs } \\
\text { in creating safety- A qualitative } \\
\text { study of handover across care } \\
\text { boundaries in emergency care } \\
\text { (Sujan } \text { et al., 2015) }\end{array}$ & $\begin{array}{l}\text { Qualitative } \\
\text { (interviews and } \\
\text { observations) }\end{array}$ & Emergency care & $\begin{array}{l}\text { Patient handovers between the } \\
\text { ambulance personnel and the } \\
\text { receiving emergency care } \\
\text { nurses }\end{array}$ & \\
\hline $\begin{array}{l}\text { 4. Safe medication management } \\
\text { in specialized home healthcare - } \\
\text { an observational study } \\
\text { (Lindblad } \text { et al., 2017) }\end{array}$ & $\begin{array}{l}\text { Qualitative } \\
\text { observational } \\
\text { study }\end{array}$ & Home care & $\begin{array}{l}\text { Home care nurses providing } \\
\text { general care to patients } \\
\text { receiving home care }\end{array}$ & \\
\hline $\begin{array}{l}\text { 5. Efficiency and thoroughness } \\
\text { trade-offs in high volume } \\
\text { organizational routines: an } \\
\text { ethnographic study of } \\
\text { prescribing safety in primary } \\
\text { care (Grant and Guthrie, 2018) }\end{array}$ & $\begin{array}{l}\text { Ethnographic } \\
\text { study }\end{array}$ & Primary care & $\begin{array}{l}\text { Safety in medication } \\
\text { prescriptions }\end{array}$ & \\
\hline $\begin{array}{l}\text { 6. An exploration of } \\
\text { workarounds and their } \\
\text { perceived impact on antibiotic } \\
\text { stewardship in the adult medical } \\
\text { ward of a referral hospital in } \\
\text { Malawi: a qualitative study } \\
\text { (Mula et al., 2019) }\end{array}$ & $\begin{array}{l}\text { Qualitative (focus } \\
\text { groups and } \\
\text { observation) }\end{array}$ & Hospital ward & $\begin{array}{l}\text { Nurses' antibiotic } \\
\text { administration in a hospital } \\
\text { ward }\end{array}$ & \\
\hline $\begin{array}{l}\text { 7. Double checking: a second } \\
\text { look (Hewitt et al., 2016) }\end{array}$ & $\begin{array}{l}\text { Large qualitative } \\
\text { study }\end{array}$ & Hospital wards & $\begin{array}{l}\text { Double checking in medication } \\
\text { administration }\end{array}$ & \\
\hline $\begin{array}{l}\text { 8. The efficiency-thoroughness } \\
\text { trade-off after implementation of } \\
\text { electronic medication } \\
\text { management: a qualitative study } \\
\text { in pediatric oncology (Baysari } \\
\text { et al., 2020) }\end{array}$ & $\begin{array}{l}\text { Qualitative } \\
\text { interview study }\end{array}$ & $\begin{array}{l}\text { A pediatric } \\
\text { oncology cancer } \\
\text { center }\end{array}$ & $\begin{array}{l}\text { A comparison of expectations } \\
\text { and experiences before and } \\
\text { after the introduction of an } \\
\text { electronic medication } \\
\text { management system }\end{array}$ & \\
\hline $\begin{array}{l}\text { 9. The ETTO principle and } \\
\text { organizational strategies: a field } \\
\text { study of ICU bed and staff } \\
\text { management (Xiao et al., 2010) }\end{array}$ & $\begin{array}{l}\text { Field study } \\
\text { (observations and } \\
\text { interviews) }\end{array}$ & The ICU & $\begin{array}{l}\text { Management of staff and } \\
\text { resources in an intensive care } \\
\text { unit }\end{array}$ & \\
\hline $\begin{array}{l}\text { 10. Providing high-quality care } \\
\text { in primary care settings: How to } \\
\text { make trade-offs (Beaulieu et al., } \\
\text { 2014) }\end{array}$ & Mixed method & $\begin{array}{l}\text { Primary care } \\
\text { practices }\end{array}$ & $\begin{array}{l}\text { Resource management to } \\
\text { provide high-quality care in } \\
\text { primary care practices }\end{array}$ & $\begin{array}{r}\text { Table 1. } \\
\text { Overview of included } \\
\text { studies }\end{array}$ \\
\hline
\end{tabular}

affects clinical quality dimensions. The categories were as following: I. Organizational factors impose forced or planned trade-offs, weighting efficiency, impacting clinical quality; II. Tradeoff visions aiming to increase quality exist in both the blunt-and the sharp end; III. Health personnels own assessments are often the most prominent vector when thoroughness is weighted; IV. Factors related to IT systems and ward guidelines lead to trade-offs. 


\section{IJHG \\ 26,3}

\begin{tabular}{|c|c|c|c|c|c|c|}
\hline & \multicolumn{2}{|c|}{ Organizational factors } & \multicolumn{2}{|c|}{ Trade-offs } & \multicolumn{2}{|c|}{ Clinical quality } \\
\hline Main categories & Categories & Sub-categories & Categories & $\begin{array}{l}\text { Sub- } \\
\text { categories }\end{array}$ & Categories & Sub-categories \\
\hline \multirow{5}{*}{$\begin{array}{l}\text { I. Organizational } \\
\text { factors related to } \\
\text { staffing, time } \\
\text { pressure and a } \\
\text { high workload, } \\
\text { imposes forced } \\
\text { or planned trade- } \\
\text { offs, weighting } \\
\text { efficiency, } \\
\text { impacting clinical } \\
\text { quality }\end{array}$} & \multirow{2}{*}{$\begin{array}{l}\text { Related to } \\
\text { economy }\end{array}$} & Wages & \multirow{5}{*}{$\begin{array}{l}\text { Trade-offs } \\
\text { challenging } \\
\text { thoroughness }\end{array}$} & \multirow[b]{2}{*}{$\begin{array}{l}\text { Trade-offs } \\
\text { imposed by } \\
\text { time } \\
\text { constraints, } \\
\text { staff shortage } \\
\text { and workload }\end{array}$} & \multirow[b]{2}{*}{$\begin{array}{l}\text { Trade-offs } \\
\text { having } \\
\text { negative } \\
\text { impact on } \\
\text { clinical } \\
\text { quality }\end{array}$} & \multirow[b]{2}{*}{$\begin{array}{l}\text { Trade-offs } \\
\text { where efficiency } \\
\text { may impact } \\
\text { clinical quality } \\
\text { negatively } \\
\text { (Choosing } \\
\text { efficiency to } \\
\text { manage task on } \\
\text { time) }\end{array}$} \\
\hline & & External funding & & & & \\
\hline & \multirow{3}{*}{$\begin{array}{l}\text { Related to } \\
\text { staffing, } \\
\text { time } \\
\text { pressure } \\
\text { and } \\
\text { workload }\end{array}$} & Limited time & & \multirow{3}{*}{$\begin{array}{l}\text { Deliberate } \\
\text { trade-offs } \\
\text { done by } \\
\text { health } \\
\text { personnel to } \\
\text { keep up } \\
\text { efficiency }\end{array}$} & \multirow{3}{*}{$\begin{array}{l}\text { Trade-offs } \\
\text { having } \\
\text { positive } \\
\text { impact on } \\
\text { clinical } \\
\text { quality }\end{array}$} & \multirow{3}{*}{$\begin{array}{l}\text { Trade-offs } \\
\text { where efficiency } \\
\text { may impact } \\
\text { clinical quality } \\
\text { positively (more } \\
\text { patients getting } \\
\text { treatment) }\end{array}$} \\
\hline & & High workload & & & & \\
\hline & & Staff shortage & & & & \\
\hline \multirow{2}{*}{$\begin{array}{l}\text { II. Trade-offs } \\
\text { between } \\
\text { efficiency and } \\
\text { thoroughness are } \\
\text { planned in both } \\
\text { the blunt-and the } \\
\text { sharp end, with } \\
\text { the aim to } \\
\text { increase quality, } \\
\text { although, } \\
\text { increased quality } \\
\text { is not always the } \\
\text { result }\end{array}$} & \multirow[t]{2}{*}{$\begin{array}{l}\text { Planned } \\
\text { measures } \\
\text { to balance } \\
\text { efficiency } \\
\text { trade-offs }\end{array}$} & $\begin{array}{l}\text { Planned measures } \\
\text { to ensure efficiency }\end{array}$ & \multirow[t]{2}{*}{$\begin{array}{l}\text { Planned } \\
\text { trade-offs }\end{array}$} & $\begin{array}{l}\text { Planned } \\
\text { trade-offs in } \\
\text { the blunt end }\end{array}$ & $\begin{array}{l}\text { Planned } \\
\text { trade-offs } \\
\text { having } \\
\text { limited } \\
\text { impact on } \\
\text { clinical } \\
\text { quality }\end{array}$ & $\begin{array}{l}\text { A planned } \\
\text { Weighting of } \\
\text { thoroughness is } \\
\text { not necessarily } \\
\text { synonymous } \\
\text { with increased } \\
\text { quality }\end{array}$ \\
\hline & & $\begin{array}{l}\text { Planned measures } \\
\text { to ensure } \\
\text { thoroughness }\end{array}$ & & $\begin{array}{l}\text { Planned } \\
\text { trade-offs in } \\
\text { the sharp end }\end{array}$ & $\begin{array}{l}\text { Planned } \\
\text { measures } \\
\text { to increase } \\
\text { quality }\end{array}$ & $\begin{array}{l}\text { Planned trade- } \\
\text { offs to increase } \\
\text { quality on an } \\
\text { organizational } \\
\text { level }\end{array}$ \\
\hline \multirow[t]{2}{*}{$\begin{array}{l}\text { III. The health } \\
\text { personnel's own } \\
\text { assessments are } \\
\text { often a more } \\
\text { prominent vector } \\
\text { than } \\
\text { organizational } \\
\text { factors when } \\
\text { thoroughness is } \\
\text { weighted }\end{array}$} & & & \multirow[t]{2}{*}{$\begin{array}{l}\text { Trade-offs } \\
\text { challenging } \\
\text { efficiency }\end{array}$} & \multirow[t]{2}{*}{$\begin{array}{l}\text { Choosing } \\
\text { thoroughness } \\
\text { over efficiency } \\
\text { to avoid } \\
\text { mistakes }\end{array}$} & $\begin{array}{l}\text { Trade-offs } \\
\text { having } \\
\text { negative } \\
\text { impact on } \\
\text { clinical } \\
\text { quality }\end{array}$ & $\begin{array}{l}\text { Trade-offs } \\
\text { where } \\
\text { thoroughness } \\
\text { may impact } \\
\text { clinical quality } \\
\text { negatively } \\
\text { (choosing } \\
\text { thoroughness } \\
\text { may affect } \\
\text { other patients } \\
\text { due to lack of } \\
\text { efficiency }\end{array}$ \\
\hline & & & & & $\begin{array}{l}\text { Trade-offs } \\
\text { having } \\
\text { positive } \\
\text { impact on } \\
\text { clinical } \\
\text { quality }\end{array}$ & $\begin{array}{l}\text { Trade-offs } \\
\text { where } \\
\text { thoroughness } \\
\text { may impact } \\
\text { clinical quality } \\
\text { positively } \\
\text { (patient safety } \\
\text { maintained) }\end{array}$ \\
\hline \multirow[t]{2}{*}{$\begin{array}{l}\text { III. Organizational } \\
\text { factors related to } \\
\text { IT-systems and } \\
\text { ward guidelines } \\
\text { forces health } \\
\text { personnel to do }\end{array}$} & \multirow[t]{2}{*}{$\begin{array}{l}\text { Factors } \\
\text { related to } \\
\text { IT-systems } \\
\text { and ward } \\
\text { guidelines }\end{array}$} & IT-systems & \multirow[t]{2}{*}{$\begin{array}{l}\text { Trade-offs } \\
\text { challenging } \\
\text { efficiency }\end{array}$} & $\begin{array}{l}\text { Trade-offs } \\
\text { done to work } \\
\text { around poorly } \\
\text { functioning } \\
\text { systems }\end{array}$ & & \\
\hline & & Ward & & Choosing & & \\
\hline \multirow[t]{2}{*}{$\begin{array}{l}\text { trade-offs to } \\
\text { battle the } \\
\text { systems }\end{array}$} & & \multirow[t]{2}{*}{ guidelines/routines } & & $\begin{array}{l}\text { thoroughness } \\
\text { over a system } \\
\text { designed to be } \\
\text { efficient }\end{array}$ & & \\
\hline & & & & $\begin{array}{l}\text { System } \\
\text { designs } \\
\text { affecting } \\
\text { efficiency } \\
\text { negatively }\end{array}$ & & \\
\hline
\end{tabular}

Table 2.

Example of analysis 


\section{Results}

The studies reviewed in this synthesis were published in the period 2010-2020. Evidence on trade-offs, organizational factors and clinical quality was retrieved from studies conducted in hospitals (emergency care, surgical wards and general wards) and primary healthcare services (home care services and primary care clinics). The research concerned nurses, hospital physicians, primary care physicians, pharmacists and medical secretaries. The results of the synthesis are presented in the order of the identified main categories.

(1) Organizational factors impose forced or planned trade-offs, weighting efficiency, impacting clinical quality

The most prominent identified factors, either imposing or leading to planned trade-offs, were limited time, high workload or staff-shortage (Xiao et al., 2010; Grant and Guthrie, 2018; Mula et al., 2019; Lindblad et al., 2017). The study conducted by Mula et al. (2019) was situated in Malawi (a low-income country), and the trade-offs identified here were highly affected by resource limitations (e.g. limited equipment and staffing). For example, during antibiotic administration, to save time, the nurses opposed medication rules by leaving the medication with the patients' family, instead of administering it right away. They further practiced the process of one nurse signing of the medication, while another nurse administered it, thus challenging the principle of accountability (Mula et al., 2019). It was acknowledged by the nurses that these trade-offs could impact the patients' safety negatively. Lindblad et al.'s (2017) study found that home care nurses often refrained from checking pre-dispensed medication and rather relied on the pre-dispensing done by their colleagues. They further skipped team meetings, which was an opportunity for safety debriefing, and chose not to check the electronic medical records, prioritizing face-to-face communication with peers to get updates on the patient' status. These trade-offs enabled them to manage their task on time, although with the risk of missing important information (Lindblad et al., 2017).

Trade-offs planned by health personnel to save time were identified in three studies (Grant and Guthrie, 2018; Mula et al., 2019; Duncan et al., 2019). In Grant and Guthrie's (2018) study, they had a high volume of prescription requests, which made it necessary to prioritize speed of processing. To handle the great workload, secretaries were assigned greater responsibilities in handling prescriptions, with limited general practitioner (GP) oversight. In clinics with lower volumes of requests, the efficiency measures were more restricted (receptionists were permitted to issue a limited range of prescriptions). In other clinics, all requests were reviewed by the GPs. In the clinics where the receptionists were granted greater responsibilities, it was recognized that this was risky in terms of a great dependence on the receptionists' knowledge. In the clinics where GPs overlooked all responsibilities themselves, it impacted the GPs' time and resulted in delays in request processing and other areas of care (Grant and Guthrie, 2018). Duncan et al. (2019) found that patients often were excluded from their own medication reviews because it was quicker for the physicians to "just do it without them." The physicians also found it difficult to discontinue medication that the patients were no longer in need for, because the time to conduct this conversation with the patient was limited (Duncan et al., 2019).

(2) Trade-off visions aiming to increase quality exist in both the blunt end and the sharp end

Two studies described how ETTOs were planned (Xiao et al., 2010; Beaulieu et al., 2014) in the blunt end (e.g. by ward managers and through ward guidelines). The primary care practices in Beaulieu et al.'s (2014) study made an ongoing effort to "make trade-offs to deliver services that met their vision of high quality care." The leaders were in this context essential in the negotiation of compromises and in achieving high internal coherence between their quality

\section{Efficiency- thoroughness trade-offs}

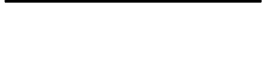


IJHG

26,3

vision and the allocation of resources. High-quality care was, in the participants' opinion, not necessarily only delivering "state of the art care," it also involved making the healthcare service accessible in a timely manner, as well as providing continuity in the delivered healthcare services (Beaulieu et al., 2014). In Xiao et al.'s (2010) study, they were trying to meet efficiency demands by admitting as many patients as possible, to be able to meet the patient surge in the ICU, as well as aiming to keep the nursing staff costs low. At the same time, they focused on providing high-quality care and endorse the well-being of the staff (Xiao et al., 2010).

Trade-offs were also planned among health personnel (in the sharp end) in two of the included studies (Grant and Guthrie, 2018; Lindblad et al., 2017). Due to a large surge of patients in the primary care clinics in Grant and Guthrie's (2018) study, speed was highly prioritized to ensure that patient requests were dealt with in a timely manner. Several measures to ensure processing speed, planned by health personnel, were identified (e.g. transferring some of the GP tasks to the receptionists, divide requests evenly between the GPs and authorizes requests using attached notes).

(3) Health personnel's own assessments are often the most prominent vectors when thoroughness is weighted

When thoroughness was weighted in the included studies, it was often despite organizational factors and not because of them (Hewitt et al., 2016; Sujan et al., 2015; Szymczak et al., 2010). For example, in Sujan et al.'s study (2015), the ward management had introduced guidelines imposing one single handover between the ambulance personnel and a dedicated handover nurse to save time and ensure that the ambulance personnel were ready for their next call. However, the ambulance personnel conducted a second handover (a secret handover) to the nurse in charge of the patient, defying ward guidelines, to ensure that all necessary information reached the nurse who was responsible for the patient's care. Both the nurse and the ambulance personnel wanted this solution, because it made them confident that all necessary information was transferred (Sujan et al., 2015). In the study of Szymczak et al. (2010), physicians avoided the hospital's newly introduced "duty-hour-regulations," which were limiting their work hours. Physicians often chose to stay at work despite reaching their hour limit, because "they had a strong sense that there was a right, thorough way to care for the patients, which took precedence over the clock." They did, for example, not leave a task half done when they had reached their time limit, but rather stayed and completed the task to minimize extra hand-offs and thereby reducing the risk of lost information. However, the physicians had doubts regarding their efficiency as clinicians as well and recognized that working long hours could compromise patient safety and contribute to physician burnout. Lastly, in the study of Hewitt et al. (2016), which concerned medication management in hospital wards, the nurses sometimes conducted triple checks (or more) before administering medication, although, double-checking was the requirement. In some situations, doublechecking was perceived as insufficient, and additional checks were therefore added to ensure safety. Double checking did, however, increase the workload, as time was spent looking for colleagues for the second sign-off (Hewitt et al., 2016).

(4) Factors related to IT systems and ward guidelines lead to trade-offs

In three studies, trade-offs induced by IT systems and ward guidelines were identified (Duncan et al., 2019; Lindblad et al., 2017; Baysari et al., 2020). In Lindblad et al.'s (2017) study, shortcomings in the IT system made communication and information exchange challenging, forcing the nursing home nurses to find creative solutions, such as leaving a copy of the medication list in the patients' homes, with handwritten notes and colored highlights to clarify the prescribed medication (Lindblad et al., 2017). In Duncan et al.'s (2019) study, the 
physicians refrained from discontinuing medication that the patient no longer needed, partly because of unclear guidance on medication discontinuation. Baysari et al. (2020) found that the new electronic medication management system, which had recently been implemented, had many positive sides (e.g. easier accessibility to patient data, improved safety, inbuilt decision support), however, nurses perceived that medication administration took more time with the new system. Furthermore, it led to delays due to log-in difficulties and slow computers. Additionally, the new system induced new types of errors (e.g. user errors) and imposed an involuntary thoroughness focus on the health personnel (Baysari et al., 2020).

\section{Discussion}

Several studies demonstrated that trade-offs were imposed by organizational factors such as a busy environment, high workload, inappropriate staffing or lack of resources. However, organizational factors such as ward routines and electronic systems were also identified. The trade-offs in this context were often done by health personnel weighing thoroughness in an environment weighing efficiency, although they did, in some studies, focus on efficiency to provide care in a timely manner.

\section{The important balance between efficiency and thoroughness}

The increased focus on efficiency, throughput and economy in healthcare services worldwide (Berg, 2005; Hammerschmid et al., 2018) is partly grounded in an ongoing increase in healthcare demands - an increase which is expected to continue in line with the prospect of an aging population over the next 50 years (Suzmanand Beard, 2011; Bloom et al., 2010). In this perspective, efficiency is, and will become, a crucial aspect in the delivery of healthcare services. This is underlined by the World Health Organization (WHO) which, in 2010, stated that to gain universal healthcare coverage for all, there is a need to improve efficiency and make better use of existing resources (WHO, 2010). Moreover, efficiency is an important aspect of healthcare quality and is reflected in three of IOM's six dimensions for healthcare quality (effective, timely and efficient) (AHRQ, 2015). Efficiency has further been identified as an important aspect of patients' perception of good healthcare quality (Doyle et al., 2013; European Patients Forum, 2017). Although health personnel's emphasis on efficiency to deliver timely care was identified in the results of this review (Grant and Guthrie, 2018; Duncan et al., 2019; Xiao et al., 2010), efficiency may become an issue if it is continuously favored over other quality dimensions (Hollnagel, 2009). A predominant focus on efficiency may be problematic for healthcare quality (Glette et al., 2017), as well as challenging health personnel's welfare and work satisfaction; moreover, it has implications for patient safety (Glette et al., 2018; Karlsson et al., 2019). This demonstrates the importance of balancing efficiency and thoroughness, as described by the ETTO principle (Hollnagel, 2009).

Mula et al.s' (2019) study was situated in a low-income country and poses a different scene in regards to ETTOs. Trade-offs here were mostly affected by organizational factors (e.g. staffing levels, resources) and lead to situations which potentially could threaten patient safety. In low-income countries, the access to resources is lower, and health personnel are to a larger degree forced to emphasize efficiency to be able to keep the healthcare services running (Aveling et al., 2015; Khan, 2013). If resource limitations force a consistent efficiency focus, the likelihood of errors happening will increase (Hollnagel, 2009). As this is an undesirable situation in any healthcare institution, the ETTO perspective is an aspect to bear in mind for future policy choices in the healthcare services (WHO, 2010).

\section{Efficiency- thoroughness trade-offs}


IJHG

26,3

Choosing thoroughness in an environment weighting efficiency - the regulatory role of health personnel

Several of the included studies demonstrated that health personnel had some degree of flexibility in efficiency-thoroughness choices, although they worked in environments that often weighted efficiency (e.g. ward routines and rules). This was demonstrated through the "secret handover" in Sujan et al.'s study (2015) and the bending of the work-hour rules in Szymczak et al.'s (2010) study, which may also be identified as workarounds. That said, this flexibility was not consistent in all studies. In Lindblad et al. (2017), for example, the nurses were to a large degree bound by time constraints and workload. A trait identified in other studies was that health personnel often felt pressured to work effectively and focus on acute needs, rather than on care-related tasks and long-term needs (Slettebø et al., 2010; Martinsen et al., 2018). However, the review found that when trade-offs weighting thoroughness was conducted, it was often conducted by health personnel in an environment emphasizing efficiency. Health personnel seemed to play a regulatory role, aiming to ensure patient safety and patient centeredness. This finding is supported by Wiig et al.'s (2014) study, which demonstrated that health personnel, and particularly nurses, were more concerned with the patients' experiences in quality improvement measures, while hospital management focused more strongly on efficiency and costs. It is conceivable that health personnel's regulatory role will become even more prominent in future healthcare services, if the pressure for efficiency continues to increase. It is necessary to gain more knowledge of this role and of health personnel's flexibility to exercise it, and also the effect it has on healthcare quality. Increased knowledge may enable us to prepare for a possible future scenario and to better understand the current situation in healthcare services worldwide.

\section{Organizational culture and the ETTO principle}

Although the included studies did not address organizational culture and the ETTO principle directly, some cultural aspects were reflected in the results. The violation of work-hour rules as identified in Szymczak et al. (2010) may be an example of how a culture has developed among physicians over time, making what previously was trade-offs, departmental norms. Such a culture has also been problematized in Halbesleben et al. (2008) where workarounds grounded in, for example, poorly functioning work routines are normalized into work practice. An important aspect to consider in this context is the eventual long-term effects workarounds or trade-offs (such as work-hour rule violations) may have on health personnel's well-being and a work practice operating closely around the patient safety margins. According to Halbesleben et al. (2008), workarounds may result from conflicting demands between elements in the system (e.g. policies, laws, regulations, protocols), but they could also result from trade-offs grounded in health personnel's values and professional codes of ethics (e.g. The Code of Medical Ethics and The Nurses' Code of Ethics (Riddick, 2003; International Council of Nurses, 2012). Overall, organizational culture (e.g. values, norms, rituals) will most likely impact efficiency-thoroughness trade-offs; however, more research is needed to understand this connection.

\section{Discussing the ETTO principle}

Hollnagel (2009) argues that one has to choose between what is efficient and what is thorough in every healthcare context. One cannot have both, but must, nevertheless, make sure that there is a balance between the two to avoid errors or adverse events. However, it has in previous studies been argued that efficiency and thoroughness actually may be maintained concurrently, for example, through better utilization of existing resources (Valdmanis et al., 2008; Tucker et al., 2008) or by introducing supportive toolkits for health personnel 
(Kapella, 2016). Moreover, Ayaad et al. (2019) found that both efficiency and quality were increased when electronic medical records were introduced to the healthcare service. Furthermore, Navarro-Espigares and Torres (2011) could not identify any trade-offs between efficiency and quality in their study on the subject. This demonstrates that the picture may be more nuanced than indicated in the ETTO principle, and the principle must therefore be applied with care. That said, the ETTO principle provides an overview of current challenges health personnel are faced with in their everyday work, challenges which may become even more current in future healthcare services in line with the increasing need for high-quality healthcare services.

\section{Strengths and limitations}

This is, to the best of our knowledge, the first thematic synthesis investigating the ETTO principle and how trade-offs affect clinical quality. Thematic literature syntheses enables the researcher to illuminate a targeted selection of findings to answer a research question (Magliocca et al., 2015; Thomas and Harden, 2008). However, as thematic syntheses aim to gather a purposive sample, rather than an exhaustive sample for this purpose (Thomas and Harden, 2008), relevant literature may remain undiscovered. This is a weakness which needs to be considered when reading these results. Moreover, a general weakness of literature reviews is that researchers define their problems in different ways (Galvan, 2017), meaning that search words used in the literature searches might yield different meanings to different individuals. Although several versions of the search words were included in the current searches, some of the words contain a great number of meanings and definitions (e.g. organizational factors and healthcare quality), which means that there may be variations in how the words are defined by different individuals. Furthermore, the inclusion of search criteria challenging the ETTO principle with an even wider scope of the search could potentially have contributed to more variations in the results and a more in-depth consideration of the ETTO principle. This perspective is, however, highlighted in the discussion. Moreover, due to the complexity of healthcare quality, it is difficult to assess a coherence between quality and external factors (such as efficiency-thoroughness trade-offs). This study did therefore aim to explore how efficiency-thoroughness trade-offs potentially affect clinical quality and does not provide information about any direct causation between the two. We suggest further research to use our results and develop studies testing direct relationship between the concepts.

\section{Conclusion}

In this study we have reviewed the literature to increase knowledge on what role organizational factors have in how health personnel make efficiency-thoroughness trade-offs, and how these trade-offs potentially affect clinical quality dimensions.

The study showed that individual healthcare professionals deal with a high number of different types of demands from their organizational surroundings that cause trade-offs which may affect healthcare quality. We found that the context, and thereby the organizational factors that health personnel are working within, will have an impact on how efficiency and thoroughness are weighted. Moreover, it was demonstrated that health personnel adapt to the situations or the context they are in and make continuous efficiency versus thoroughness assessments with subsequent trade-offs. In the perspective of the clinical quality domains, the domains effective healthcare services and timely care to patients were perceived to be the most dominant, while health personnel were trying to safeguard the domains patient centeredness and patient safety within an environment weighing efficiency.

\section{Efficiency- thoroughness trade-offs}


IJHG

26,3

262

Balancing resources and healthcare demands while providing healthcare quality is integral in health personnel's daily work. We found that organizational factors affect this balancing act, yet there is limited research on this subject. Trade-offs with negative quality consequences may be unnoticed and may normalize over time. For policymakers and healthcare managers, this is a signal that calls for stronger interest and more research into the role of organizational factors and the condition under which healthcare professionals work. Regulatory framework (e.g. guidelines), staffing level, competence, IT systems and supplies are examples of factors that healthcare managers and policymakers make decisions about, which, our review indicated, are factors that can result in tradeoffs, with potential impact on clinical quality. More research should also investigate how trade-offs result in positive quality implications and which organizational factors are key in this.

Due to the expected increase in healthcare demands over the next years, the assessment of efficiency-thoroughness trade-offs may become an even more relevant subject in future healthcare services. There is therefore a need to gain more knowledge in this area, both within the practice field and through increased research on the subject, thus contributing to optimize quality in healthcare services worldwide.

\section{References}

AHRQ (2015), "Six Domains of Health Care Quality", Content last reviewed November 2018, Agency for Healthcare Research and Quality, Rockville, MD, available at: https://www.ahrq.gov/ talkingquality/measures/six-domains.html.

Aveling, E.L., Kayonga, Y., Nega, A. and Dixon-Woods, M. (2015), "Why is patient safety so hard in low-income countries? A qualitative study of healthcare workers' views in two African hospitals", Globalization and Health, Vol. 11, p. 6.

Ayaad, O., Alloubani, A., EA, A.L., Farhan, M., Abuseif, S., Al Hroub, A. and Akhu-Zaheya, L. (2019), "The role of electronic medical records in improving the quality of health care services: comparative study", International Journal of Medical Informatics, Vol. 127, pp. 63-67.

Bate, P. (2008), Organizing for Quality: The Improvement Journeys of Leading Hospitals in Europe and the United States, Radcliffe, Oxford.

Baysari, M.T., Van Dort, B.A., Prgomet, M., Zheng, W.Y., Raban, M.Z., Dalla-Pozza, L., McCullagh, C. and Westbrook, J. (2020), "The efficiency-thoroughness trade-off after implementation of electronic medication management: a qualitative study in pediatric oncology", International Journal for Quality in Health Care, Vol. 32 No. 8, pp. 511-516.

Beaulieu, M.-D., Geneau, R., Del Grande, C., Denis, J.-L., Hudon, E., Haggerty, J.L., Bonin, L., Duplain, R., Goudreau, J. and Hogg, W. (2014), "Providing high-quality care in primary care settings: how to make trade-offs", Canadian Family Physician Medecin de Famille Canadien, Vol. 60 No. 5, pp. e281-e289.

Berg, O. (2005), Fra Politikk Til Økonomikk, Den norske helsepolitikks utvikling det siste sekel, Oslo.

Bloom, D.E., Canning, D. and Fink, G. (2010), "The greying of the global population and its macroeconomic consequences", Twenty-first Century Society, Vol. 5 No. 3, pp. 233-242.

Braithwaite, J., Clay-Williams, R., Nugus, P. and Plumb, J. (2013), "Health care as a complex adaptive system", in Hollnagel, E., Braithwaite, J. and Wears, R.L. (Eds), Resilient Health Care, Ashgate, Farnham, pp. 58-73.

Busse, R., Klazinga, N., Panteli, D. and Quentin, W. (Eds) (2019), Improving Healthcare Quality in Europe: Characteristics, Effectiveness and Implementation of Different Strategies, European Observatory on Health Systems and Policies, Copenhagen.

Critical Appraisal Skills Programme (2019), CASP (Qualitative Checklist) [online], available at: https:// casp-uk.net/referencing/ (accessed 18 September 2020). 
Davies, H.T.O., Nutley, S.M. and Mannion, R. (2000), "Organisational culture and quality of health care", Quality in Health Care, Vol. 9 No. 2, p. 111.

Doyle, C., Lennox, L. and Bell, D. (2013), "A systematic review of evidence on the links between patient experience and clinical safety and effectiveness", BMJ Open, Vol. 3 No. 1, e001570.

Duncan, P., Cabral, C., McCahon, D., Guthrie, B. and Ridd, M.J. (2019), "Efficiency versus thoroughness in medication review: a qualitative interview study in UK primary care", British Journal of General Practice, Vol. 69 No. 680, e190.

European Patients Forum (2017), Patients' Perceptions of Quality in Healthcare, European Patients, Forum.

Galvan, J.L. (2017), Writing Literature Reviews : A Guide for Students of the Social and Behavioral Sciences, 7th ed, England, Routledge, NY London, New York, NY.

Glette, M.K., Aase, K. and Wiig, S. (2017), "The relationship between understaffing of nurses and patient safety in Hospitals, ${ }^{a}$ A literature review with thematic analysis", Open Journal of Nursing, Vol. 07 No. 12, p. 43.

Glette, M.K., Røise, O., Kringeland, T., Churruca, K., Braithwaite, J. and Wiig, S. (2018), "Nursing home leaders' and nurses' experiences of resources, staffing and competence levels and the relation to hospital readmissions - a case study”, BMC Health Services Research, Vol. 18 No. 1, p. 955.

Grant, S. and Guthrie, B. (2018), "Efficiency and thoroughness trade-offs in high-volume organisational routines: an ethnographic study of prescribing safety in primary care", BMJ Quality and Safety, Vol. 27 No. 3, p. 199.

Halbesleben, J.R., Wakefield, D.S. and Wakefield, B.J. (2008), "Work-arounds in health care settings: literature review and research agenda", Health Care Management Review, Vol. 33 No. 1, pp. 2-12.

Halvorsen, K., Dihle, A., Hansen, C., Nordhaug, M., Jerpseth, H., Tveiten, S., Joranger, P. and Ruud Knutsen, I. (2020), "Empowerment in healthcare: a thematic synthesis and critical discussion of concept analyses of empowerment", Patient Education and Counseling, Vol. 103 No. 7, pp. $1263-1271$.

Hammerschmid, G., Van de Walle, S., Andrews, R. and Mostafa, A.M.S. (2018), "New Public Management reforms in Europe and their effects: findings from a 20-country top executive survey", International Review of Administrative Sciences, Vol. 85 No. 3, pp. 399-418.

Hewitt, T., Chreim, S. and Forster, A. (2016), "Double checking: a second look", Journal of Evaluation in Clinical Practice, Vol. 22 No. 2, pp. 267-274.

Hollnagel, E. (2009), The ETTO Principle: Efficiency-Thoroughness Trade-Off: Why Things that Go Right Sometimes Go Wrong, CRC press, Boca Raton.

Hong, Q.N., Pluye, P., Fabregues, S., Bratlett, G., Boardmand, F., Cargo, M., Dagenais, P., Gagnon, M.P., Griffiths, F., Nicolau, B., Cathain, A.O., Rousseau, M.-C. and Vedel, I. (2018), Mixed Methods Appraisal Tool, Mc Gill, Department of Family Medicine, Quebec.

International Council of Nurses (2012), "The ICN code of ethics for nurses", International Council of Nurses, Geneva, pp. 1-10.

Kapella, K.M.D. (2016), "Caring for patients outside the clinic: a toolkit for improving quality and efficiency", Journal of the American Medical Directors Association, Vol. 17 No. 3, p. B13.

Karlsson, A.-C., Gunningberg, L., Bäckström, J. and Pöder, U. (2019), "Registered nurses' perspectives of work satisfaction, patient safety and intention to stay - a double-edged sword", Journal of Nursing Management, Vol. 27 No. 7, pp. 1359-1365.

Keliddar, I., Mosadeghrad, A.M. and Jafari-Sirizi, M. (2017), "Rationing in health systems: a critical review", Medical Journal of the Islamic Republic of Iran, Vol. 31, p. 47.

Khan, M.I. (2013), "Developing a safety culture in developing countries", in, International Conference, 'Safety, Construction Engineering \& Project Management (ICSCEPM)', Islamabad. 
IJHG

26,3

Li, D.G., Wong, G.X., Martin, D.T., Tybor, D.J., Kim, J., Lasker, J., Mitty, R. and Salem, D. (2017), "Attitudes on cost-effectiveness and equity: a cross-sectional study examining the viewpoints of medical professionals", BMJ Open, Vol. 7 No. 7, e017251.

Lindblad, M., Flink, M. and Ekstedt, M. (2017), "Safe medication management in specialized home healthcare - an observational study", BMC Health Services Research, Vol. 17 No. 1, p. 598 .

Magliocca, N., Rudel, T., Verburg, P., McConnell, W., Ole, B., Mertz, O., Gerstner, K., Heinimann, A., Erle, b. and Ellis, E. (2015), "Synthesis in land change science: methodological patterns, challenges, and guidelines", Journal: Reg Environ Change, Vol. 15, pp. 211-226.

Martinsen, B., Mortensen, A.S. and Norlyk, A. (2018), "Nordic homecare nursing from the perspective of homecare nurses - a meta-ethnography", British Journal of Community Nursing, Vol. 23 No. 12 , pp. 597-604.

Moher, D., Shamseer, L., Clarke, M., Ghersi, D., Liberati, A., Petticrew, M., Shekelle, P., Stewart, L.A. and Group, P.-P. (2015), "Preferred reporting items for systematic review and meta-analysis protocols (PRISMA-P) 2015 statement", Systematic Reviews, Vol. 4 No. 1, p. 1.

Mosadeghrad, A.M. (2014), "Factors influencing healthcare service quality", International Journal of Health Policy and Management, Vol. 3 No. 2, pp. 77-89.

Mula, C.T., Human, N. and Middleton, L. (2019), "An exploration of workarounds and their perceived impact on antibiotic stewardship in the adult medical wards of a referral hospital in Malawi: a qualitative study", BMC Health Services Research, Vol. 19 No. 1, p. 64.

National Heart Lung and Blood Institute, "Quality assessment tool for observational cohort and crosssectional studies”, available at: https://www.nhlbi.nih.gov/health-topics/study-qualityassessment-tools (accessed 15 September 2020).

Navarro-Espigares, J.L. and Torres, E.H. (2011), "Efficiency and quality in health services: a crucial link", The Service Industries Journal, Vol. 31 No. 3, pp. 385-403.

Riddick, F.A. Jr (2003), "The code of medical ethics of the american medical association”, The Ochsner Journal, Vol. 5 No. 2, pp. 6-10.

Slettebø, A., Kirkevold, M., Andersen, B., Pedersen, R., Halvorsen, K., Nordhaug, M. and Nortvedt, P. (2010), "Clinical prioritizations and contextual constraints in nursing homes-a qualitative study", Scandinavian Journal of Caring Sciences, Vol. 24 No. 3, pp. 533-540.

Sujan, M., Spurgeon, P. and Cooke, M. (2015), "The role of dynamic trade-offs in creating safety-a qualitative study of handover across care boundaries in emergency care", Reliability Engineering and System Safety, Vol. 141, pp. 54-62.

Suzman, R. and Beard, J. (2011), Gobal Health and Aging, World Health Organization, National Institute of Health, WHO; US National Institute of Aging.

Szymczak, J.E., Brooks, J.V., Volpp, K.G. and Bosk, C.L. (2010), "To leave or to lie? Are concerns about a shift-work mentality and eroding professionalism as a result of duty-hour rules justified?", The Milbank Quarterly, Vol. 88 No. 3, pp. 350-381.

Thomas, J. and Harden, A. (2008), "Methods for the thematic synthesis of qualitative research in systematic reviews", BMC Medical Research Methodology, Vol. 8, p. 45.

Tucker, A.L., Singer, S.J., Hayes, J.E. and Falwell, A. (2008), "Front-line staff perspectives on opportunities for improving the safety and efficiency of hospital work systems", Health Services Research, Vol. 43 No. 5 Pt 2, pp. 1807-1829.

Valdmanis, V.G., Rosko, M.D. and Mutter, R.L. (2008), "Hospital quality, efficiency, and input slack differentials”, Health Services Research, Vol. 43 No. 5 Pt 2, pp. 1830-1848.

van Leeuwen, K.M., van Loon, M.S., van Nes, F.A., Bosmans, J.E., de Vet, H.C.W., Ket, J.C.F., Widdershoven, G.A.M. and Ostelo, R. (2019), "What does quality of life mean to older adults? A thematic synthesis”, PloS One, Vol. 14 No. 3, e0213263. 
WHO (2010), The World Health Report: Health Systems Financing: The Path to Universal Coverage, World Health Oreganization, Geneva.

Wiig, S., Aase, K., von Plessen, C., Burnett, S., Nunes, F., Weggelaar, A.M., Anderson-Gare, B., Calltorp, J., Fulop, N. and For, Q.-T. (2014), "Talking about quality: exploring how 'quality' is conceptualized in European hospitals and healthcare systems", BMC Health Services Research, Vol. 14 No. 1, p. 478.

Xiao, T., Sanderson, P., Clayton, S. and Venkatesh, B. (2010), "The ETTO principle and organisational strategies: a field study of ICU bed and staff management”, Cognition, Technology and Work, Vol. 12 No. 2, pp. 143-152.

\section{Attachments: Attachment I. Overview of searches}

The Appendix file is available online for this article.

\section{Corresponding author}

Malin Knutsen Glette can be contacted at: Malinknutsen.glette@hvl.no

For instructions on how to order reprints of this article, please visit our website:

www.emeraldgrouppublishing.com/licensing/reprints.htm

Or contact us for further details: permissions@emeraldinsight.com 